\title{
Caveat time traveller
}

\section{Future-proof.}

\section{Gregory Benford}

He was easy to spot - clothes from the twenty-first century, dazed look. I didn't have to say anything. He blurted out, "Look, I'm from the past, a time traveller. But I get snapped back there in a few minutes."

"I know." We stood in a small street at the edge of the city, dusk creeping in. Distant, glazed towers gleamed in the sunset and pearly lights popped on down along the main road. Jaunters always chose to appear at dawn or dusk, where they might not be noticed but could see a town. No point in transporting into a field somewhere, which could be any time at all, even the far past. Good thing he couldn't see the city rubble, too. Or realize this was how I made my living.

His mouth twisted in surprise. "You do? I thought I might be the first to come here. To this time."

I gave him a raised eyebrow. "No. There was another last week."

"Really? The professor said the other experiments failed. They couldn't prove they'd been into the future at all."

They always want to talk, though they'd learn more with their mouths closed.

He rattled on, "I have to take something back, to show I was here. Something -"

"How about this?" I pulled out a slim metal cylinder. "Apply it to your neck five times a day and it extracts cancer precursors. In your era, that will extend your average lifetime by several years."

His eyebrows shot up. "Wow! Sure He reached for it but I snatched it back.

"What do I get in exchange?" I said mildly.

That startled him. "What? I don't have anything you could use..." He searched his pockets in the old fashioned wide-label jacket. "How about money?" A fistful of bills.

"I'm not a collector, and those are worthless now, inflated away in value."

The time jaunter blinked. "Look, this is one of the first attempts to jump forward and back. I don't have - "
"I know, we've seen jaunters from your era already. Enough to set up a barter system. That's why I had this cancercanceller."

Confusion swarmed in his face. "Lady, I'm just a guinea pig here. A volunteer. They didn't give me-"

I pointed. "Your watch is a pleasant anachronism, I'll take that." I gave him the usual ceramic smile.

He sighed with relief. “Great - ” But I kept the cylinder away from him.

"Yes," I said crisply. My left eye told me the chron-senser network was picking up an approaching closure. I leaned over and kissed him on the mouth. "Thanks! It's such a thrill to meet someone from the ancient times."

That shook him even more. Best to keep them off balance.

"So how do I get that cancer thing?" he said, eyes squinting with a canny cast.

"Let me have your clothes," I shot back.

"What? You want me ... naked?"

"I can use them as antiques. That cancer stick is pretty expensive, so I'm giving you a good deal."

He nodded and started shucking off his coat, pants, shoes, wallet, coins, cash, set of keys. Reached for his shorts -

"Never mind the underwear."

"Oh." He handed me the bundle and I gave him the cancer stick. "Hey, thanks. I'll be back. We just wanted to see if -"

Pop. He vanished. The cancer stick rattled on the ground. It was

"That's an opener offer, not the whole deal." A broader smile.

He glanced around, distracted by my outfit. I always wore it when the chronsenser networks said there was a jaunt about to happen. Their old dress styles were classic, so they weren't prepared for my peekaboo leggings, augmented breasts and perfectly symmetric face. The lipstick was outrageous for our time, but fit right into the twenty-first century kink.

He raised a flat ceramic thing and it whirred. Taking pictures, like the rest. They still hadn't learned, whenever this guy came from.

"Your pictures won't develop," I told him with a seemingly sympathetic smile.

"Huh? They gave me this -"

"You've heard of time paradoxes, yes? Space-time resolves those nicely. You can't take back knowledge that alters the past. All that gets erased automatically, a kind of information cleansing. Very convenient physics."

Startled, he glanced at his compact camera. "So ... it'll be blank?" just a prop, of course. Cancer was even worse now.

They never caught on. Of course, they don't have much time. That made the fifth this month, from several different centuries.

Time was like a river, yes. Go with the flow, it's easy. Fight against the current and space-time strips you of everything you're carrying back - pictures, cancer stick, memories. He would show up not recalling a thing. Just like the thousands of others I have turned into a nifty little sideline.

The past never seemed to catch on. Still, they stimulated interest in those centuries where time jaunters kept hammering against the laws of physics, like demented moths around a light bulb.

I hefted the clothes and wallet. These were in decent condition, grade 0.8 at least. They should fetch a pretty price. Good; I needed to eat soon. Time paid off, after all. A sucker born every minute, and so many, many moments in the rich past. novelist. His best known novel is Timescape. 